\title{
A desalination system with efficiency approaching the theoretical limits
}

Philip A. Davies ${ }^{1 *}$, James Wayman ${ }^{1}$, Chioma Alatta ${ }^{1}$, Kim Nguyen $^{1}$ and Jamel Orfi ${ }^{2}$

${ }^{1}$ Sustainable Environment Research Group, School of Engineering and Applied Science, Aston University, Birmingham, B4 7ET, UK

${ }^{2}$ Mechanical Engineering Department, College of Engineering, King Saud University, PO Box 800, Riyadh, 11421, KSA

*corresponding author: Tel +44 121204 3724, p.a.davies@ aston.ac.uk

Presented at EUROMED 2015. Desalination for Clean Water and Energy, Palermo May 2015

Abstract: The objective of this project is to design a new desalination system with energy efficiency approaching the theoretical thermodynamic limit - even at high recovery ratio. The system uses reverse osmosis (RO) and a batch principle of operation to overcome the problem of concentration factor which prevents continuous-flow RO systems from ever reaching this limit and thus achieving the minimum possible specific energy consumption, SEC. Batch operation comprises a cycle in 3 phases: pressurisation, purge and refill. Energy recovery is inherent to the design. Unlike in closedcircuit desalination, no feedwater is added to the pressure circuit during the pressurisation phase. The batch configuration is compared to standard configurations such as continuous single-stage RO (with energy recovery) and closed-circuit desalination (CCD). Theoretical analysis has shown that the new system is able to use $33 \%$ less energy than closed-circuit desalination at recovery ratio of $80 \%$. A prototype has been constructed using readily available parts and tested with feedwater salinities and recovery ratios ranging from $2000-5000 \mathrm{ppm}$ and $17.2-70.6 \%$ respectively. Results compare very well against the standard configurations. For example, with feedwater containing $5000 \mathrm{ppm}$ $\mathrm{NaCl}$ and recovery ratio of $69 \%$, a hydraulic SEC of $0.31 \mathrm{kWh} / \mathrm{m}^{3}$ was obtained - better than the minimum theoretically possible with a single-stage continuous flow system with energy recovery device.

Key words: solar, RO, brackish water, high recovery, high efficiency, batch desalination, sustainable development 


\section{Symbols and abbreviations}

\begin{tabular}{|l|l|l|}
\hline Symbol & Unit & Description \\
\hline & & \\
\hline $\mathrm{n}$ & $\mathrm{kmol}$ & Total number of moles \\
\hline $\mathrm{n}_{0}$ & $\mathrm{kmol}$ & Initial of moles of water \\
\hline $\mathrm{n}_{1}$ & $\mathrm{kmol}$ & Final of moles of water \\
\hline $\mathrm{n}_{\text {out }}$ & $\mathrm{kmol}$ & Moles of water removed \\
\hline $\mathrm{n}_{\mathrm{s}}$ & $\mathrm{kmol}$ & Moles of solute \\
\hline $\mathrm{n}_{\mathrm{w}}$ & $\mathrm{kmol}$ & Moles of water remaining \\
\hline & & \\
\hline $\mathrm{P}$ & $\mathrm{kPa}$ & Osmotic pressure of liquid in vessel \\
\hline $\mathrm{P}_{0}$ & $\mathrm{kPa}$ & Osmotic pressure of feedwater \\
\hline $\mathrm{r}$ & & Recovery ratio \\
\hline $\mathrm{R}$ & $\mathrm{kJ} / \mathrm{kmol} \mathrm{K}$ & Universal gas constant \\
\hline $\mathrm{T}$ & $\mathrm{K}$ & Absolute temperature \\
\hline $\mathrm{V}_{0}$ & $\mathrm{~m}^{3}$ & Initial volume \\
\hline $\mathrm{V}_{1}$ & $\mathrm{~m}^{3}$ & Final volume \\
\hline $\mathrm{V}_{\mathrm{s}}$ & $\mathrm{m}^{3}$ & Volume of feedwater supplied \\
\hline $\mathrm{W}$ & $\mathrm{kJ}$ & Work done \\
\hline $\mathrm{X}$ & & Mole fraction \\
\hline$\mu$ & $\mathrm{kJ} / \mathrm{kmol}$ & Chemical potential \\
\hline & & \\
\hline $\mathrm{CCD}$ & & Closed circuit desalination \\
\hline $\mathrm{ECR}$ & & Energy consumption ratio \\
\hline $\mathrm{ERD}$ & & Energy recovery device \\
\hline $\mathrm{RO}$ & & Reverse osmosis \\
\hline $\mathrm{SEC}$ & & Specific energy consumption \\
\hline & & \\
\hline
\end{tabular}




\section{Introduction}

Efficient desalination systems are important for sustainable development. Access to improved drinking water was among the Millennium Development Goals; and thankfully the percentage of world population having such access increased from $76 \%$ in 1990 to $89 \%$ in $2012\left(\right.$ UN $\left.^{1}\right)$. Nonetheless, this still leaves some 800 million people without access to clean water. The Millennium Development Goals have recently been superseded by Sustainable Development Goals which likewise underscore the importance of access to clean water and sanitation ${ }^{2}$. According to Sachs ${ }^{3}$, the overarching objectives of sustainable development include economic prosperity and social inclusion for disadvantaged members of society. By boosting water supplies for industry, and by making clean water accessible to more and more people, desalination can contribute to the accomplishment of the Sustainable Development Goals.

Nevertheless, desalination also poses hazards to the environment. Among methods of supplying freshwater, it is among the most energy consumptive. Moreover it produces harmful by-products of reject brine. Further, in inland applications, desalination may deplete groundwater sources. For these reasons it is important to: (1) reduce the energy consumption of desalination and (2) increase the recovery of freshwater from the process. But these two requirements generally conflict: energy consumption tends to increase with recovery ratio ${ }^{4}$.

This paper presents a concept of desalination that is capable in principle of reconciling this conflict to the maximum extent possible, using a batch process to overcome the configuration loss inherent in conventional continuous systems. Our objectives are to:

i. Show theoretically that the batch-RO arrangement can approach the thermodynamic efficiency limit in desalination of brackish water, and

ii. Construct and test a prototype using readily available parts, to give preliminary experimental evidence of this goal being achieved.

The project has been implemented by Masters of Engineering (M.Eng) students at Aston University, as part of their degree programme.

\section{Theory}

To meet the first objective, we first present the thermodynamic theory to show what the efficiency limit is, both in general and with respect to specific system configurations. Because this paper deals with desalination of brackish water, thermodynamic theory relating to dilute solutions will be used. The efficiency of the system will be maximum when the SEC is minimum; therefore we have to consider the minimum possible SEC, which is the minimum work $\mathrm{W}$ needed to remove pure water from a saline solution, and is related to the chemical potential $\mu$. We consider the situation where a fraction $r$ of pure water is removed gradually from an initial volume $\mathrm{V}_{0}$ of dilute saline solution, with initial and final states at standard temperature and pressure. Thus the minimum rate of work per mole removed, $d W / d n_{\text {out }}(\mathrm{kJ} / \mathrm{kmol})$, is given by the chemical potential of pure water, minus that of the water in the solution undergoing desalination, and depends on the mole fraction $x$ of water in the solution via the basic thermodynamic relation ${ }^{5}$ : 


$$
\frac{d W}{d n_{\text {out }}}=\mu(l)-\mu(\operatorname{soln})=-R T \ln x
$$

Where $R$ is the gas constant, $T$ is absolute temperature, and mole fraction $x=n_{w} / n$, with $n_{w}$ being the number of moles of water remaining in the solution, and $n$ being the total number of moles of water and solute in the solution $n=n_{w}+n_{s}$. Using the fact that $n_{s} / n$ is small for the dilute solution allows the approximation:

$$
\frac{d W}{d n_{\text {out }}}=R T \frac{n_{s}}{n}
$$

As water is removed, the number of moles of solute in the solution $n_{s}$ remains constant, while the total number of moles of water decreases according to the number of moles of water removed such that $d n=-d n_{\text {out }}$. Thus integration of eq.[2] gives the total work needed to remove $n_{o}-n_{1}$ moles as:

$$
\Delta W=-R T n_{s} \ln \frac{n_{1}}{n_{0}}
$$

where $n_{0}$ and $n_{l}$ are respectively the initial and final number of moles of water present in the solution. The dilute solution is considered to have constant density, such that the molar ratio in eq [3] is equal to the ratio of final and initial volumes: $V_{1} / \mathrm{V}_{0}$. Moreover, since SEC is conventionally defined per volume of water removed, to get SEC we divide $\Delta \mathrm{W}$ by the change in volume $\mathrm{V}_{0}-\mathrm{V}_{1}$ which is equal to the initial volume $\mathrm{V}_{0}$ times the recovery ratio $r$. Therefore the ideal minimum SEC is:

$$
\mathrm{SEC}_{\text {ideal }}=R T \frac{n_{s}}{r V_{o}} \ln \frac{1}{(1-r)}
$$

The van't Hoff expression for dilute solutions states that $\mathrm{P}_{0} \mathrm{~V}_{0}=\mathrm{n}_{s} \mathrm{RT}$, so this equation can finally be rewritten in terms of the initial osmotic pressure $\mathrm{P}_{0}$ as:

$$
\mathrm{SEC}_{\text {ideal }}=\frac{P_{0}}{r} \ln \frac{1}{(1-r)}
$$

The energy consumption ratio (ECR) can be conveniently defined as the ratio of the energy that the plant really consumes to the ideal consumption.

$$
\mathrm{ECR}=\frac{\mathrm{SEC}_{\text {real }}}{\mathrm{SEC}_{\text {ideal }}}
$$

We note that in practical seawater desalination, ECR as low as 2 is now being achieved ${ }^{6}$. For brackish water, however, ECR may reach a value of ten or more ${ }^{7,8}$. 
We can now consider theoretical ECR values for two systems of interest: a batch system as used in this study, and the closed-circuit desalination (CCD) arrangement that has been used elsewhere, ${ }^{9}$. These systems are represented in essence as stirred vessels in Fig 1 (a) and (b) respectively. The mode of operation is such that saline feedwater is supplied at pressure $P$ by a pump, driving permeate through the membrane wall to the right. Once the concentration of salt has increased by the required amount, pressure is no longer applied, and the feed is used to displace (purge) the concentrate to drain. Then the vessel is refilled and cycle repeats through the three phases of pressurisation, purge and refill.

In each case, we show how the pressure will vary during the pressurisation phase (during which the essential work is done) and integrate this pressure with volume supplied by the feed pump, to calculate the SEC and ECR. For the purpose of calculation of minimum work and SEC, it is assumed that $P$ is only just sufficient to overcome the osmotic pressure. In this simplified analysis, it is also assumed that the rejection of salt is $100 \%$ (i.e. the permeate is pure water). The volume of each of the two vessels in Fig 1 is $\mathrm{V}_{0}$ and the volume of feed supplied after a certain time is $V_{s}$. It can be seen that the two systems are similar except that, in the case of Fig 1(a), there is a piston to prevent the incoming feed from mixing with the solution already in the vessel.

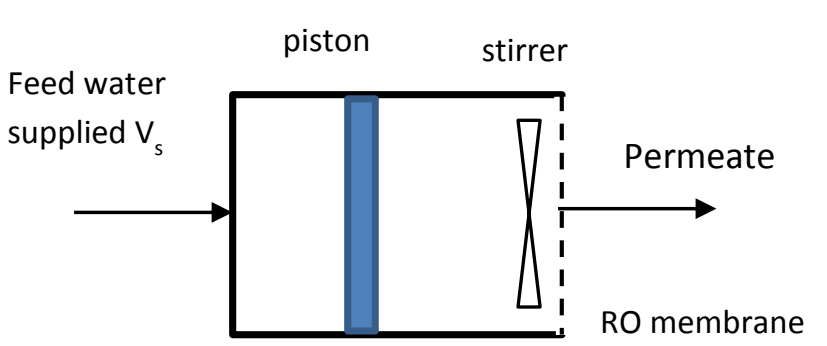

(a) Batch-RO

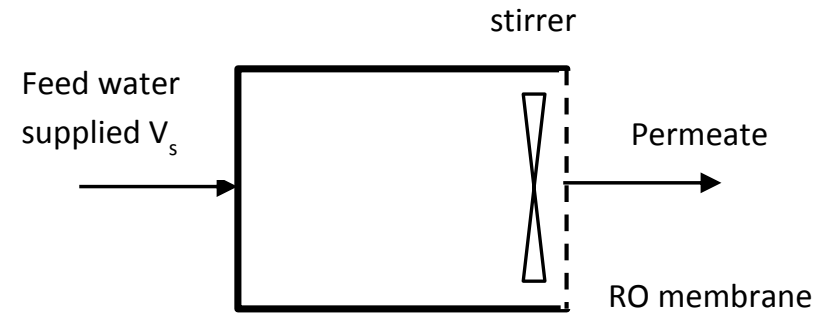

(b) CCD

Fig 1. Essential aspects of the (a) batch-RO and (b) CCD systems, represented as stirred vessels. The use of a sliding piston differentiates the batch-RO system, serving to keep the feedwater supplied from the pump separate from the pressurised saline water undergoing reverse osmosis.

In the case of the batch-RO system of Fig $1(a)$, each incremental volume $\mathrm{dV}_{\mathrm{s}}$ of feedwater supplied will cause a corresponding decrease of the stirred volume of saline water to the right of the piston, causing an increase in concentration and osmotic pressure in inverse proportion to the volume remaining (according to the van't Hoff expression). The evolution of pressure with $\mathrm{V}_{\mathrm{s}}$ therefore follows a hyperbolic curve, as shown in Fig 2(a), according to the equation:

$$
\frac{P}{P_{o s m}}=\frac{V_{0}}{V_{0}-V_{s}}=\frac{1}{1-V_{s} / V_{0}}
$$

Fig 2(a) also shows the recovery ratio $r$ achieved at the end of the cycle, which is equal to the volume of freshwater recovered, divided by the total feedwater supplied. Freshwater is recovered during the period that the piston moves to the right and is thus equal to the volume of feed $V_{s}$ supplied 
during this period. The total feedwater supplied over the whole cycle is equal to $V_{0}$, because after supplying feed $\mathrm{V}_{\mathrm{s}}$ to the vessel, a further small volume $\mathrm{V}_{\mathrm{s}}-\mathrm{V}_{0}$ must be supplied to purge the vessel of the concentrate to the right of the piston. Consequently:

$$
r=\frac{V_{s}}{V_{0}}
$$

In the CCD system of Fig 1(b), the situation is slightly different. Each incremental volume supplied $\mathrm{dV}_{\mathrm{s}}$ will add a corresponding amount of salt to the vessel. The concentration and osmotic pressure will therefore increase linearly with the volume of liquid supplied, as shown in Fig 2(b), according to the equation:

$$
\frac{P}{P_{0}}=\frac{V_{0}+V_{s}}{V_{0}}=1+\frac{V_{s}}{V_{0}}
$$

And in this case, the total feed water supplied equals $\mathrm{V}_{\mathrm{s}}$ during the pressurisation phase of the cycle, plus $\mathrm{V}_{0}$ during the purge phase, resulting in recovery:

$$
r=\frac{V_{s}}{V_{0}+V_{s}}=\frac{V_{s} / V_{0}}{1+V_{s} / V_{0}}
$$

To get the SEC for the batch system of Fig 1(a), we carry out the integration of eq.[7] with respect to $\mathrm{V}_{\mathrm{s}}$ and express the result in terms of the recovery ratio $r$, giving:

$$
\mathrm{SEC}=\frac{P_{0}}{r} \ln \frac{1}{(1-r)}
$$

Whereas for the CCD system of Fig 1(b) we integrate eq.[9] to get ${ }^{11}$ :

$$
\mathrm{SEC}=P_{0}\left[1+\frac{r}{2(1-r)}\right]
$$

Eq.[11] is identical to eq [5], showing that the system of Fig 1(a) is theoretically capable of achieving the theoretical minimum SEC, whereas Fig 1(b) results in a higher SEC. In practice, losses will cause each system to achieve lower SEC than eqs.[11] and [12] suggest. Nonetheless, in so far as losses will tend to affect both systems equally, it is expected that the batch-RO system will provide lower practical SEC than CCD, with greater divergence at higher recovery ratios as shown in Fig 3 . The difference in performance can be attributed to the fact that, in Fig1(b), incoming feedwater mixes with saline water at higher concentration already inside the vessel. Such mixing is an irreversible process and represents a sacrifice of available work within the system.

Analysis of minimum SEC for continuous single and multi-stage systems, with and without energy recovery devices (ERD), has been carried out by $\mathrm{Li}^{12}$, and by Qiu and Davies ${ }^{11}$. The key result for a single-stage continuous system with ERD is that, to overcome osmotic pressure, the feed pressure must be increased by a minimum ratio of $1 /(1-r)$ corresponding to the concentration factor between feed inlet and concentrate outlet. The minimum SEC for this case is thus: 


$$
\mathrm{SEC}=P_{o s m} \frac{1}{(1-r)}
$$

Fig 3 shows ECR values calculated by dividing SEC values from each of eqs [11], [12] and [13] by the ideal minimum of eq.[5]. It is seen that at low $r$ all three systems give similar ECR close to 1 , but at higher $r$ divergence occurs. Thus at $r=80 \%$, the CCD requires $50 \%$ more energy input and the continuous flow system requires $150 \%$ more energy input than the ideal minimum represented by the batch system.
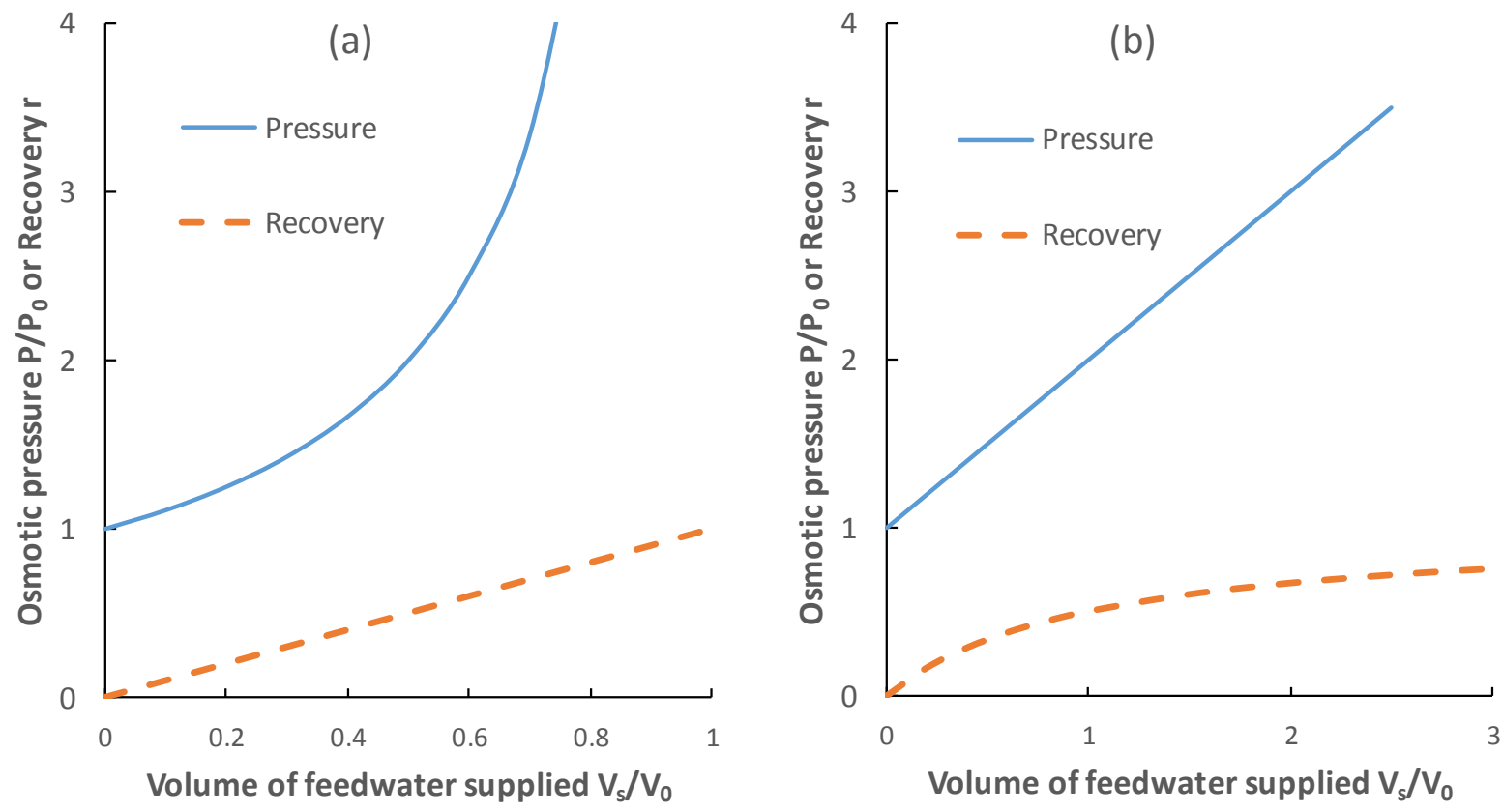

Figure 2: Evolution of osmotic pressure, and achieved recovery ratio, with feedwater volume supplied to vessel in: (a) batch-RO system as in Fig 1(a); and (b) CCD system as in Fig 1(b). The osmotic pressure $P$ is normalised against that of the feedwater $\mathrm{P}_{0}$; and the volume $\mathrm{V}_{\mathrm{s}}$ supplied is normalised against the vessel volume $\mathrm{V}_{0}$.

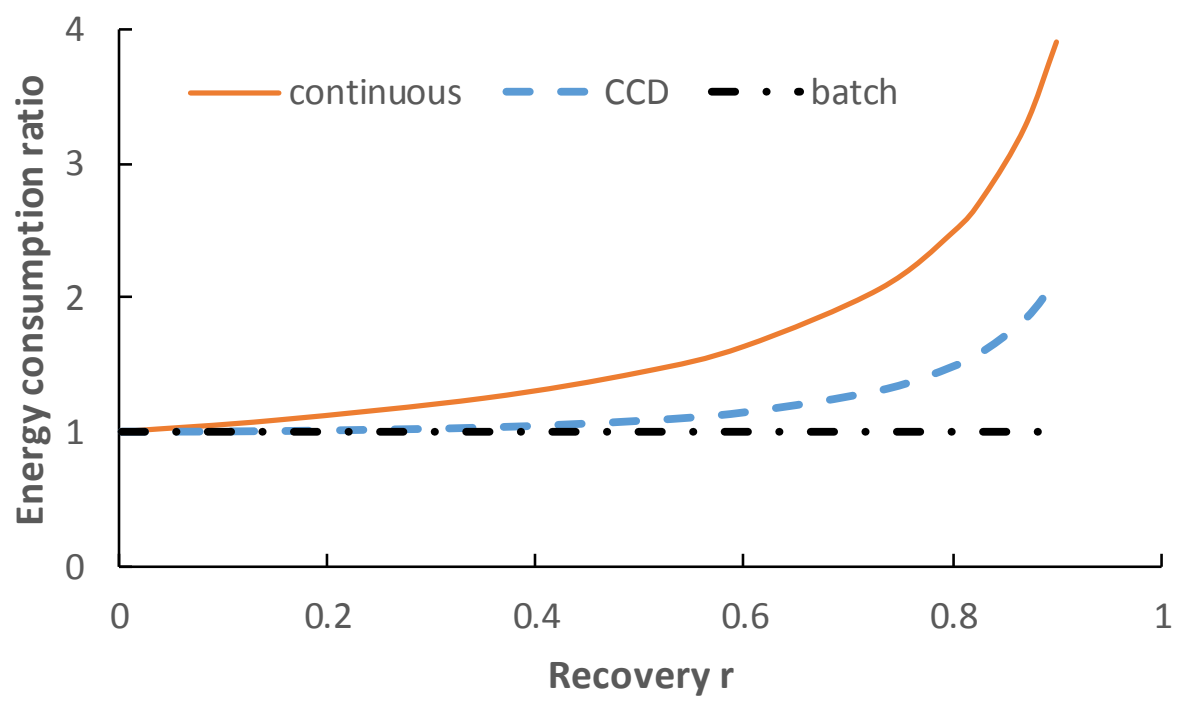

Figure 3: Energy consumption ratios (ECR) vs recovery, for three different RO configurations under idealised assumptions: single-stage continuous with energy recovery, $\mathrm{CCD}$ and batch-RO. 


\section{Design realisation}

Having explained the theoretical rationale behind the design, we now describe how it has been constructed and tested in practice. As already shown in Fig 1(a), the concept consists in essence of a pressurised batch of fluid acting against a semi-permeable RO membrane. Nonetheless, the area of membrane provided in the arrangement of Fig 1 (a) would be very small. It is necessary to increase this area, and this is achieved by means of a recirculation loop that includes a spiral-wound reverse osmosis module giving much larger area. Fig. 4 shows the practical arrangement and the sequence of operation consisting of the pressurisation, purge and refill phases. Note that the refill phase is achieved by restoring the piston to its original position, such that the saline water is exchanged back to the top side of the piston.

(a) Pressurisation

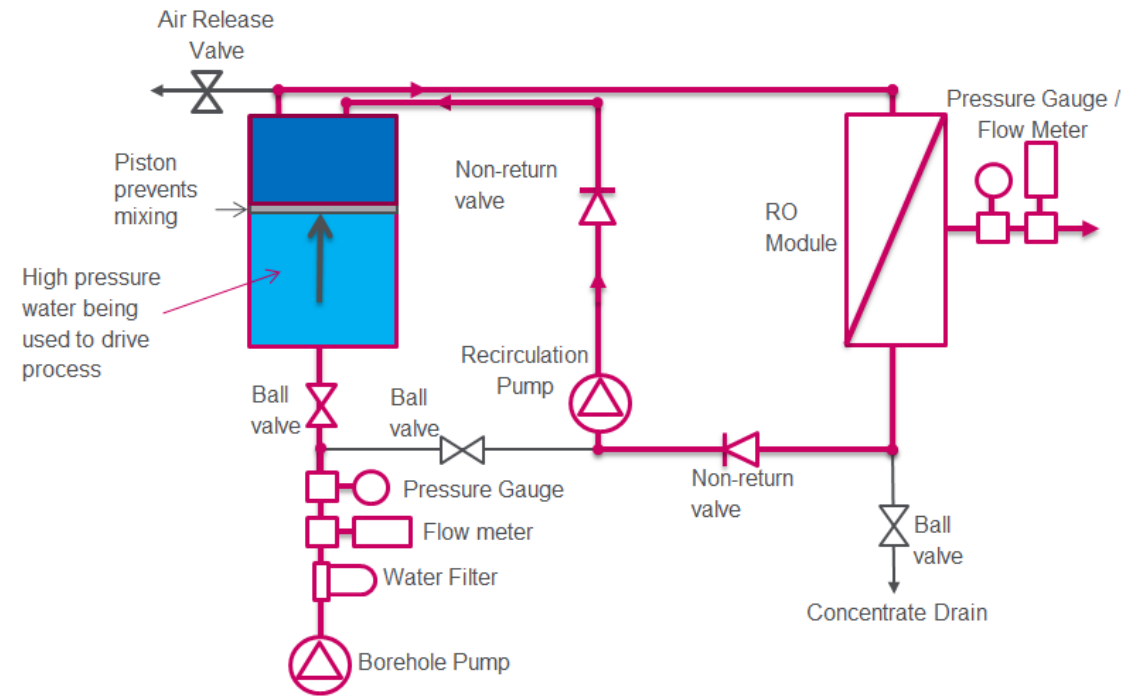

(b) Purge

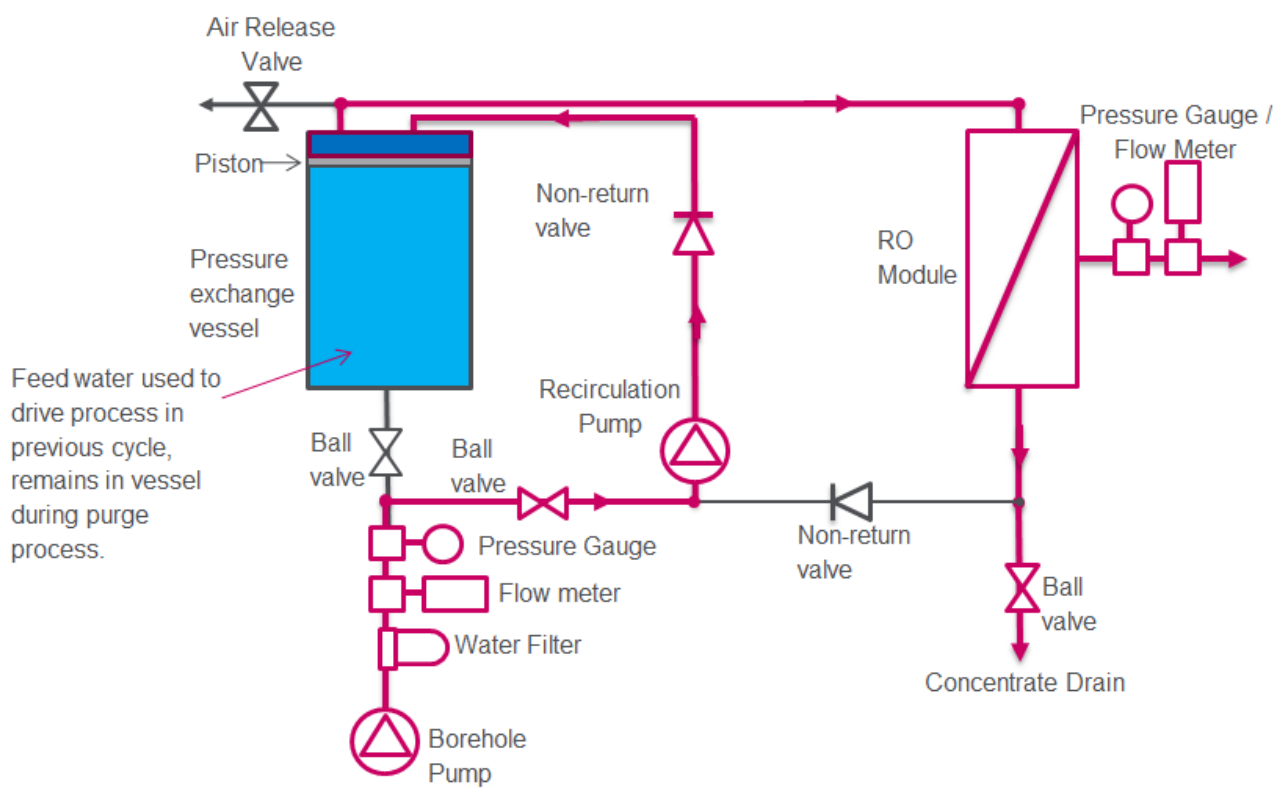


(c) Refill

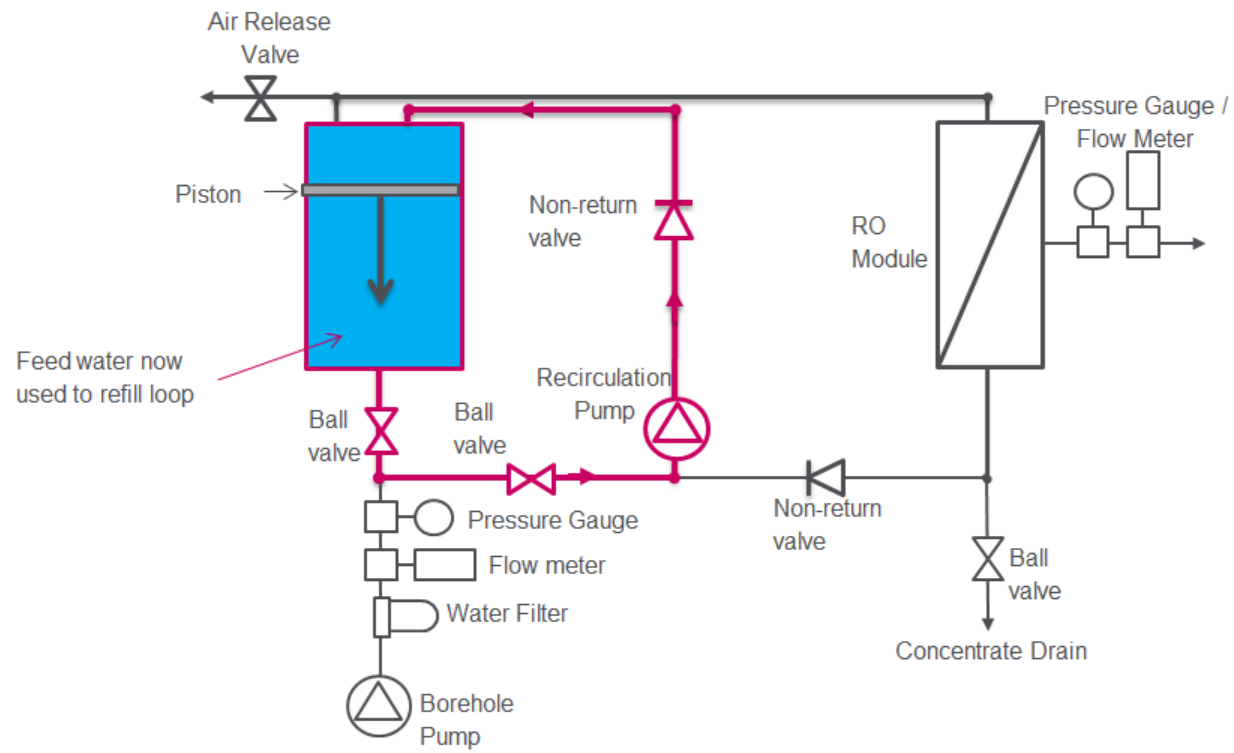

Figure 4: Arrangement and sequence of operation of the system in three phases: (a) Pressurisation - the borehole pump feeds saline water at pressure to the pressure exchange vessel (left), driving the piston upward, while the recirculation pump sends water through a loop comprising the RO module (right) and the upper volume of the pressure exchange module. Analogous to the stirrer in Fig 1(a), the recirculation serves to keep the concentration in this loop homogeneous. (b) Purge - the water in the loop has become more concentrated and is displaced by feedwater to restore the initial concentration. (c) Refill - with assistance from the recirculation pump, feedwater beneath the piston moves to its upper side as the piston descends helped by its own weight. Finally the cycle recommences. 


\section{Detailed description of equipment}

A corrosion-resistant framework of dimensions $2 \mathrm{~m}$ high $\mathrm{x} 1 \mathrm{~m}$ wide $\mathrm{x} 1 \mathrm{~m}$ deep was constructed as a platform for the test rig components (Fig. 5). The framework was made from aluminium struts, which were cut to size using a hacksaw, and assembled in-house using M5 hex bolts and right-angled corner brackets. All remaining components were directly and securely mounted to the structure.

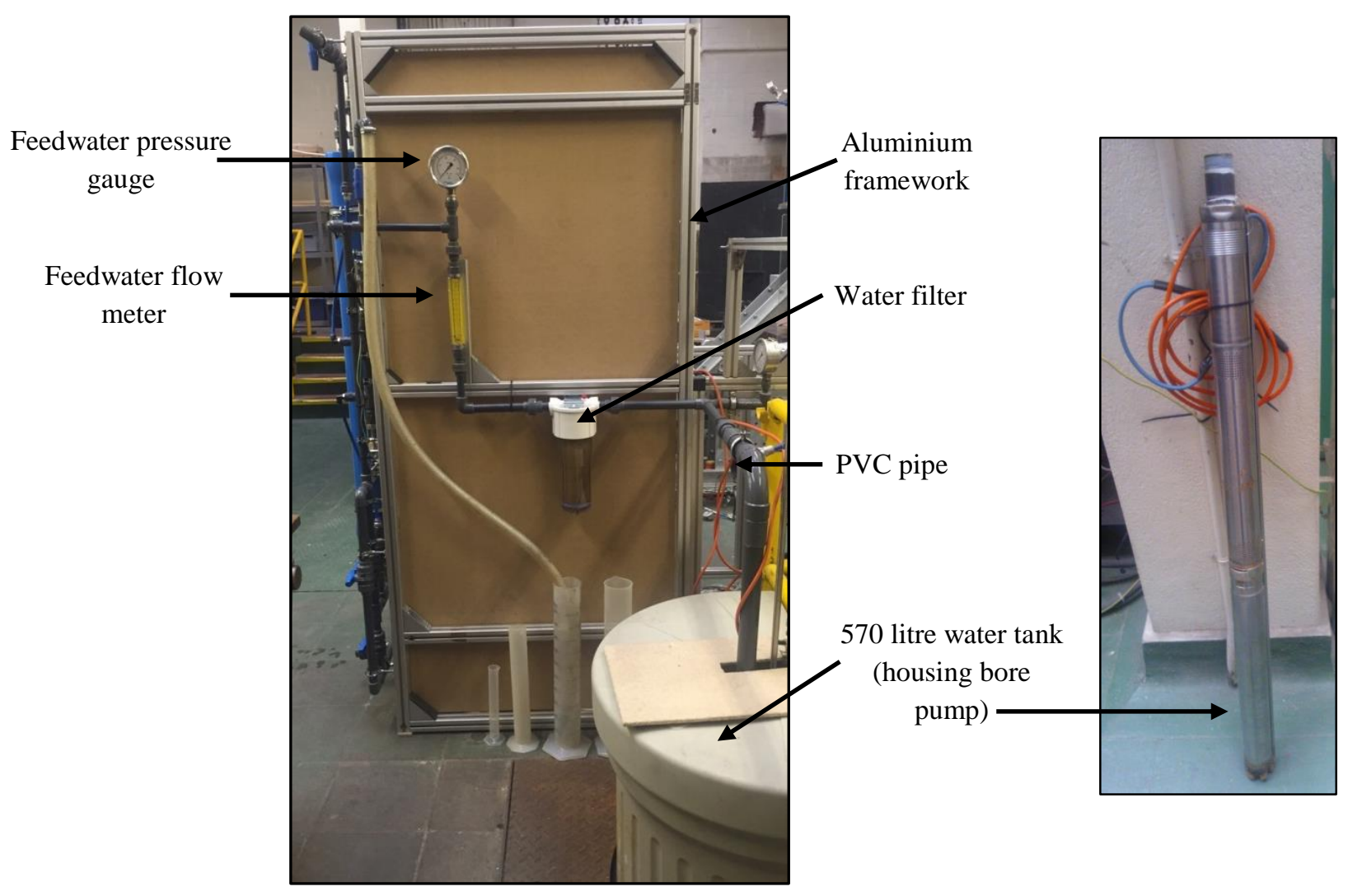

Figure 5a: Finished prototype test rig (side view) 


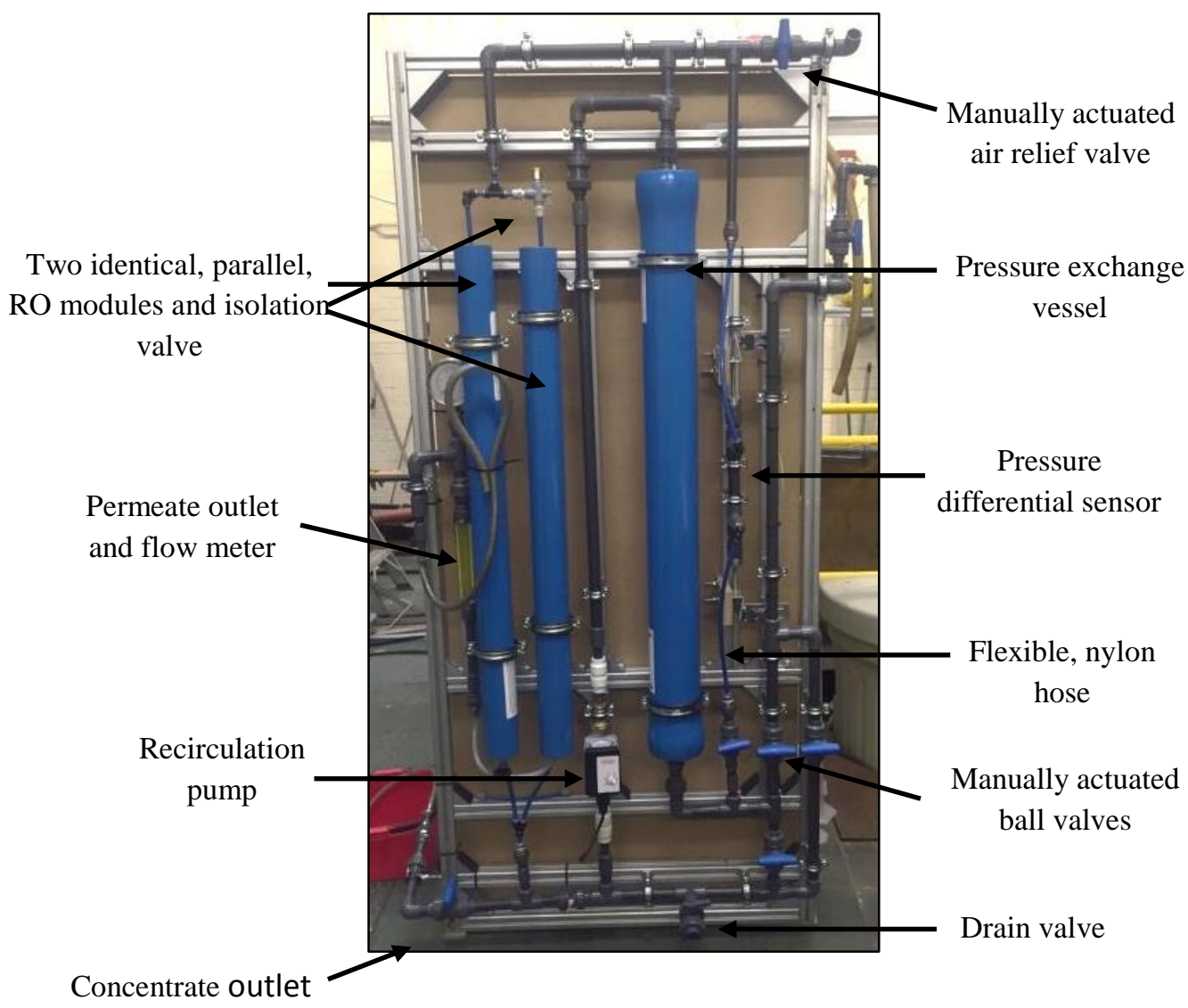

Figure 5b: Finished prototype test rig (front view)

Most of the pipework was of $1 / 2$ or $3 / 4$ inch polyvinyl chloride (PVC) type and standard solvent weld fittings were used, rated to 16 bar. PVC components were selected due to their availability, low cost, and excellent chemical and corrosion resistance. Their smooth bore offered optimum flow characteristics whilst helping eliminate the build-up of scale. For experimental purposes, the valves in this rig were manually operated ball valves. (In future versions these may be replaced by automated valves).

A 4-inch diameter, glass fibre, RO pressure vessel, with a volumetric capacity of approximately 7.9 litres, was repurposed to create a pressure exchange cylinder; designed to house a changeable piston. The piston served both to (i) isolate the batch of fluid undergoing reverse osmosis from that being used to drive the process, and (ii) set the recovery ratio according to the volume occupied by the piston. Three different pistons were thus designed to give nominal recovery ratios of $30 \%, 60 \%$ and $70 \%$ respectively (actual recovery ratios achieved varied from these values). The pistons were made on a lathe from high density polyethylene (HDPE) chosen for its low water absorption, and good impact, chemical and corrosion resistance (Fig.6). 


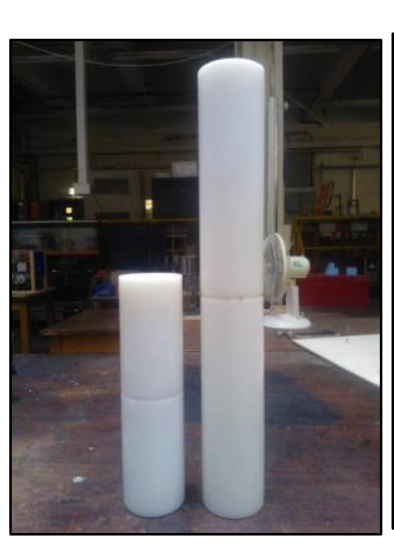

flexibility during early tests

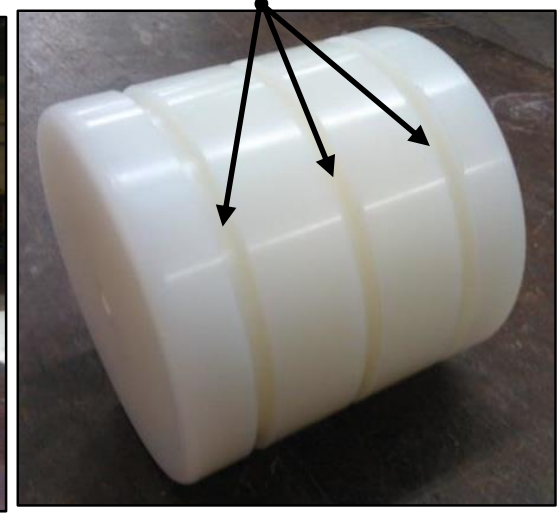

Piston dimensions

\begin{tabular}{|c|c|}
\hline Piston length & $\begin{array}{c}\text { Nominal } \\
\text { Recovery Ratio }\end{array}$ \\
\hline $0.1 \mathrm{~m}$ & $70 \%$ \\
\hline $\begin{array}{c}0.476 \mathrm{~m} \\
(0.376 \mathrm{~m}+0.1 \mathrm{~m})\end{array}$ & $60 \%$ \\
\hline $\begin{array}{c}0.785 \mathrm{~m} \\
(0.685 \mathrm{~m}+0.1 \mathrm{~m})\end{array}$ & $30 \%$ \\
\hline
\end{tabular}

Figure 6: HDPE pistons of lengths $0.1,0.376$ and $0.685 \mathrm{~m}$ to provide different recovery ratios

A groove at the centre of each piston accommodated a single, nitrile, O-ring, to seal and separate the fluid being used to drive the process from that undergoing purification. The use of a single O-ring avoided the development of any air-fluid pressure-drop across the seal, which could have resulted in an O-ring becoming dislodged during operation. To preserve the life of the O-rings and ensure the free-movement of pistons within the pressure cylinder, silicone grease was applied to the surfaces of these components before testing.

An electro-mechanical sensor was custom-built to electrically isolate the bore pump at the end of the pressurisation cycle, thus avoiding system over pressurisation. Control circuitry was designed to respond to the rapid change in pressure which occurred across the piston (located in the pressure exchange vessel), when it reached its end of travel.

A central heating circulation pump was repurposed to: 1) return the concentrate leaving the RO membrane/s to the pressure exchange vessel during pressurisation and, 2) re-prime the pressure exchange vessel at the end of each cycle. A central heating pump was selected as it was an affordable and widely available option which was simple to install and operate, and was capable of operating at a low pressure and flow. Whilst susceptible to corrosion from highly concentrated saline water, this type of pump was considered acceptable for the purpose of experimentation.

A DC helical rotor borehole pump was used for pressurisation and purging purposes. This positive displacement pump (Grundfos SQF 0.6-2) was selected for its ability to reliably produce flow at high pressures, in a corrosive environment. The pump was powered directly from a solar array simulator (Agilent Technologies E4360A). This specialist power supply was designed to simulate the currentvoltage curve of a solar photovoltaic array under various environmental conditions.

Two identical polyamide thin-film composite reverse osmosis membranes were utilised for testing (Filmtec BW30). These modules were 2.5-inch diameter $\times 40$-inch long and capable of operating at up to 41 bar; with a specified flow rate and salt rejection of $1.4 \mathrm{~m}^{3} /$ hour and $99.5 \%$ respectively. Further details of the mechanical and electrical construction may be found in reference 15. 


\section{Experimental procedure}

Sodium chloride solutions were made up in the laboratory with tap water at concentrations of 2000, 3000 and $5000 \mathrm{ppm}$. The variable parameters for the tests were: (i) feedwater concentration (ii) recovery ratio and (iii) supply pressure and thus membrane flux. The third parameter was varied by adjusting pump flow (with the help of a relief valve) and also by increasing the number of RO modules from 1 to 2 , thus decreasing the membrane flux by providing a larger area. When two modules were used they were connected in parallel. Note that due to the dead volume in each module, the number of modules also had an effect on the recovery ratio achieved.

The sequence of operations in each test followed that of Fig. 4. During each test run, feedwater pressure and permeate volume production were manually recorded at periodic time increments over the pressurisation phase, and an average permeate total dissolved salt (TDS) concentration was recorded at the end of each batch by means of a conductivity meter. To mitigate anomalies and maximise the reliability of results, each run was repeated 3 or 4 times and averages were taken to yield the final results for each test corresponding to a given set of parameters. The duration of the pressurisation phase varied from 50 to $590 \mathrm{~s}$, with 8 to 35 sets of measurements being taken in each case. In total, 15 tests were carried out, important parameters of which are summarised in Table 1.

\section{Results}

A graph of feed pressure vs permeate volume was plotted for each test. These graphs enabled cumulative hydraulic work to be calculated by integration under the curve (see example in Fig 7). Based on eq.[5], the ideal work was also calculated corresponding to the integral under the curve of osmotic pressure (based on the van't Hoff expression) as also shown in Fig 7. Thus values of SEC were found by dividing the hydraulic work done, by the volume of permeate collected. This means that SEC presented in this paper does not take into account pump inefficiencies. Neither was the work done by the recirculation pump taken into account. The results for hydraulic SEC varied from 0.135 to $0.337 \mathrm{kWh} / \mathrm{m}^{3}$ as shown in Table 1 .

Flux was worked out by dividing the permeate volume by the duration of the cycle and membrane area, and varied from 6.9 to $24.2 \mathrm{l} / \mathrm{m}^{2}$.hr (Table 1). SEC decreased as pressure and flux were reduced (Fig.8). Low pressure and flux tended to increase salinity of the permeate (Table 1). 


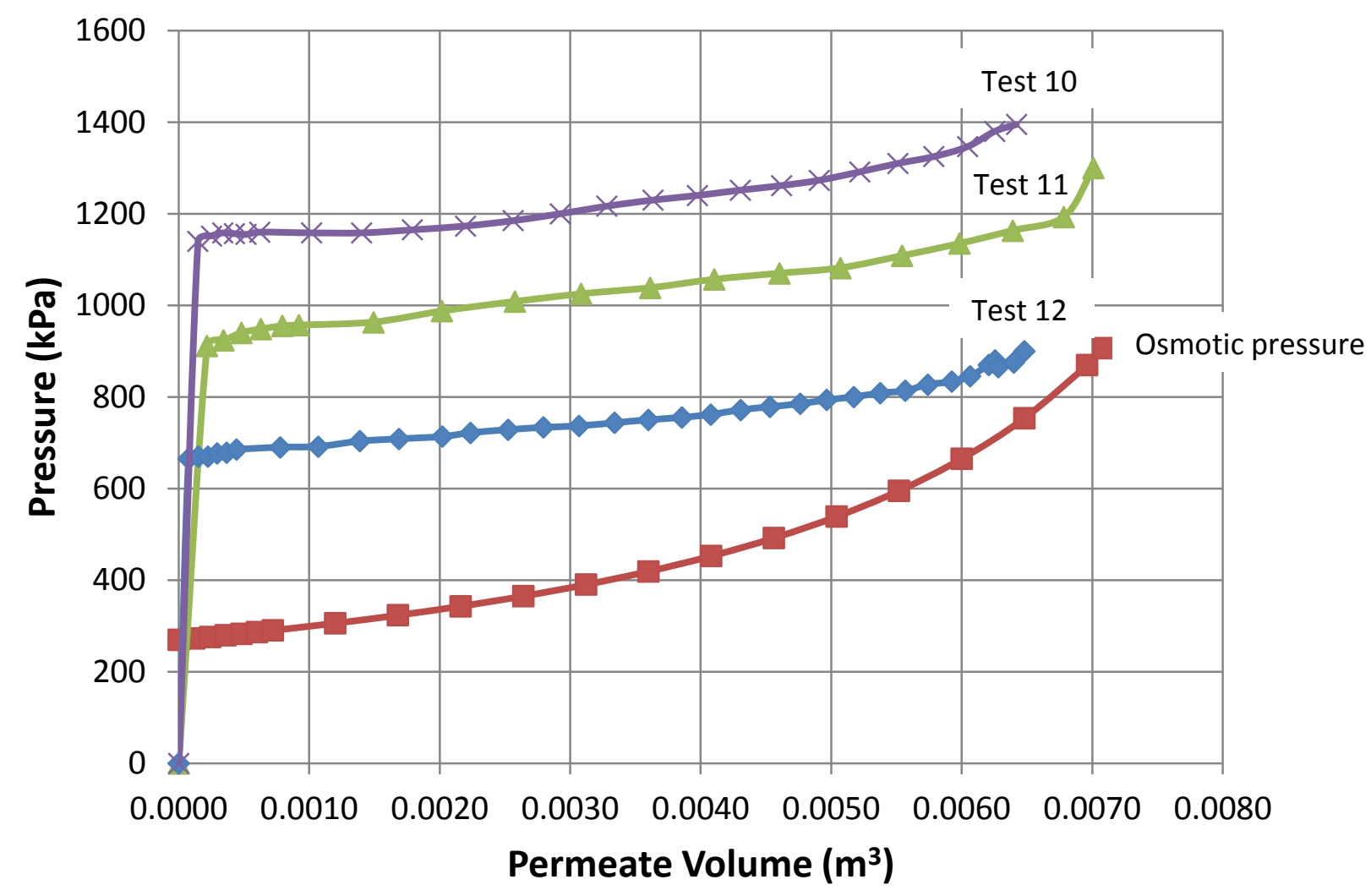

Figure 7: Example of measured feed pressure against permeate volume with different system configurations, and ideal $\mathrm{p}-\mathrm{V}$ curve based on van't Hoff expression (feed water at 3500 ppm, nominal recovery $70 \%$ ). Similar curves were obtained for the remaining tests in Table 1. 
Table 1: Summary of results for SEC according to salinity of feed $\mathrm{NaCl}$ solution and recovery ratio. The nominal recovery ratios correspond to the different pistons detailed in Fig.6. Different numbers of RO modules and system settings allowed different pressures to be achieved. SEC values as calculated by integration under p-V curves e.g. Fig

\begin{tabular}{|c|c|c|c|c|c|c|c|c|c|c|c|c|}
\hline \multirow[t]{2}{*}{$\begin{array}{l}\text { Test } \\
\text { No. }\end{array}$} & \multicolumn{2}{|c|}{ Feed salinity (ppm) } & \multirow{2}{*}{$\begin{array}{l}\text { Initial } \\
\text { Osmotic } \\
\text { pressure } \\
(\mathrm{kPa})\end{array}$} & \multicolumn{2}{|c|}{$\begin{array}{l}\text { Nominal Recovery ratio } \\
\text { (\%) }\end{array}$} & \multirow{2}{*}{$\begin{array}{l}\text { Number } \\
\text { of RO } \\
\text { modules }\end{array}$} & \multirow{2}{*}{$\begin{array}{l}\text { Max } \\
\text { pressure } \\
(\mathrm{kPa})\end{array}$} & \multirow{2}{*}{$\begin{array}{l}\text { Duration of } \\
\text { pressur- } \\
\text { isation } \\
\text { phase }(\mathrm{s})\end{array}$} & \multirow{2}{*}{$\begin{array}{l}\text { Number of } \\
\text { measure- } \\
\text { ments }\end{array}$} & \multirow{2}{*}{$\begin{array}{l}\text { Average } \\
\text { flux } \\
\left(\mathrm{L} \mathrm{m}^{-2} \mathrm{hr}^{-1}\right)\end{array}$} & \multirow{2}{*}{$\begin{array}{l}\text { Hydraulic } \\
\text { SEC } \\
\text { measured } \\
\left(\mathrm{kWh} / \mathrm{m}^{3}\right)\end{array}$} & \multirow{2}{*}{$\begin{array}{l}\text { Permeate } \\
\text { salinity } \\
\text { (ppm) }\end{array}$} \\
\hline & Nominal & Actual & & Nominal & Actual & & & & & & & \\
\hline 1 & 2000 & 2074 & 154 & 30 & 40.3 & 2 & 923 & 50 & 8 & 19.6 & 0.218 & 576 \\
\hline 2 & 2000 & 2134 & 154 & 60 & 57.3 & 2 & 1017 & 130 & 12 & 20.4 & 0.243 & 270 \\
\hline 3 & 2000 & 2118 & 154 & 70 & 69.6 & 2 & 1050 & 250 & 18 & 19.4 & 0.272 & 248 \\
\hline 4 & 3500 & 3526 & 270 & 30 & 17.2 & 1 & 923 & 70 & 9 & 20.5 & 0.220 & 640 \\
\hline 5 & 3500 & 3487 & 270 & 30 & 33.3 & 2 & 1040 & 70 & 9 & 14.9 & 0.257 & 833 \\
\hline 6 & 3500 & 3526 & 270 & 30 & 19.8 & 2 & 532 & 90 & 10 & 6.9 & 0.135 & 1001 \\
\hline 7 & 3500 & 3537 & 270 & 60 & 66.6 & 1 & 1385 & 230 & 17 & 24.2 & 0.323 & 386 \\
\hline 8 & 3500 & 3467 & 270 & 60 & 53.1 & 2 & 1125 & 150 & 13 & 17.2 & 0.277 & 435 \\
\hline 9 & 3500 & 3526 & 270 & 60 & 50.4 & 2 & 830 & 211 & 18 & 11.6 & 0.196 & 402 \\
\hline 10 & 3500 & 3496 & 270 & 70 & 70.6 & 1 & 1395 & 390 & 25 & 22.8 & 0.337 & 348 \\
\hline 11 & 3500 & 3559 & 270 & 70 & 69.5 & 2 & 1300 & 290 & 20 & 16.7 & 0.286 & 449 \\
\hline 12 & 3500 & 3526 & 270 & 70 & 64.2 & 2 & 900 & 590 & 35 & 7.6 & 0.208 & 537 \\
\hline 13 & 5000 & 4960 & 385 & 30 & 33.4 & 2 & 1310 & 70 & 9 & 13.6 & 0.281 & 1002 \\
\hline 14 & 5000 & 4979 & 385 & 60 & 51.2 & 2 & 1400 & 190 & 15 & 12.7 & 0.297 & 684 \\
\hline 15 & 5000 & 4989 & 385 & 70 & 68.9 & 2 & 1437 & 390 & 25 & 13.1 & 0.314 & 627 \\
\hline
\end{tabular}


(a)

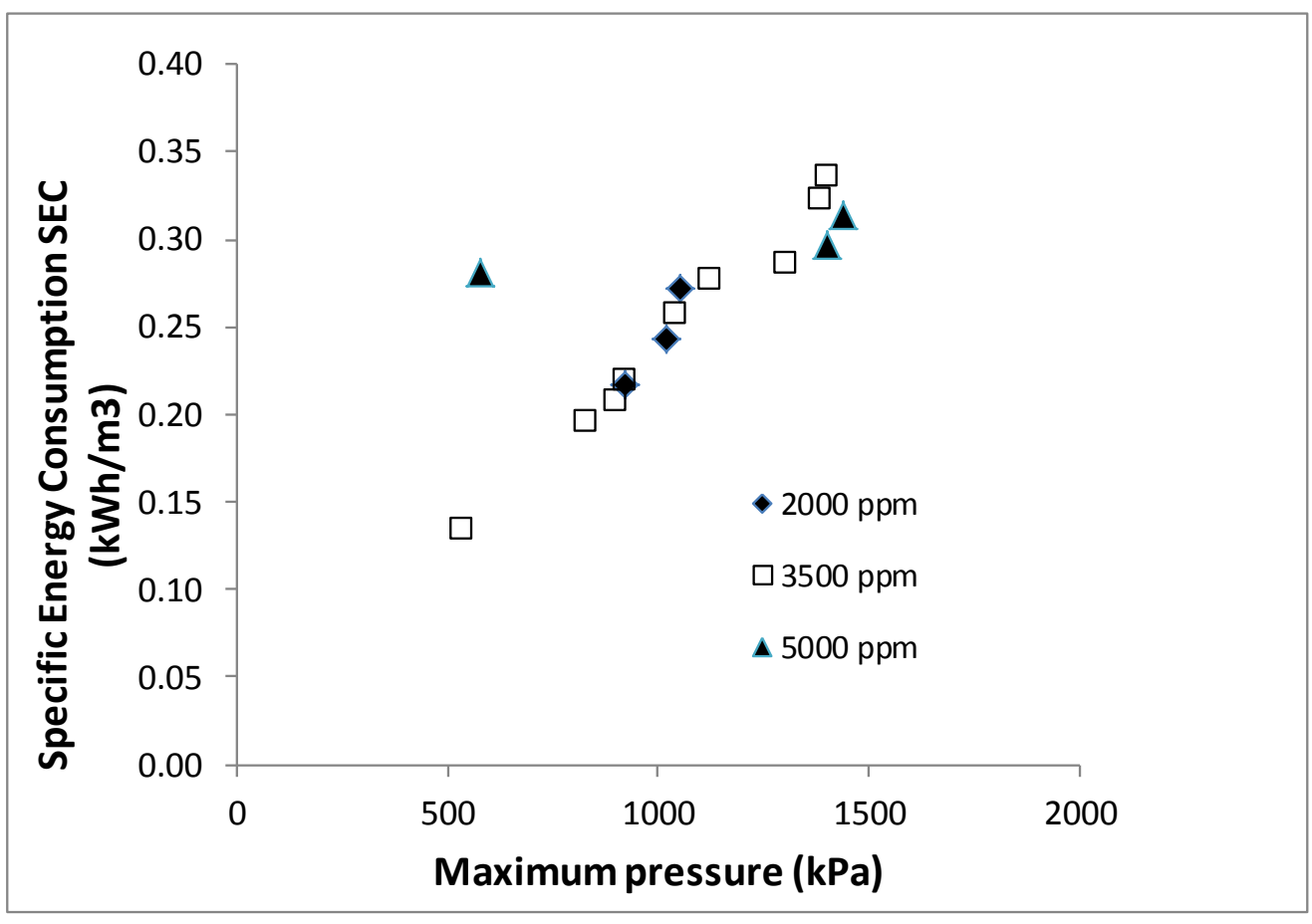

(b)

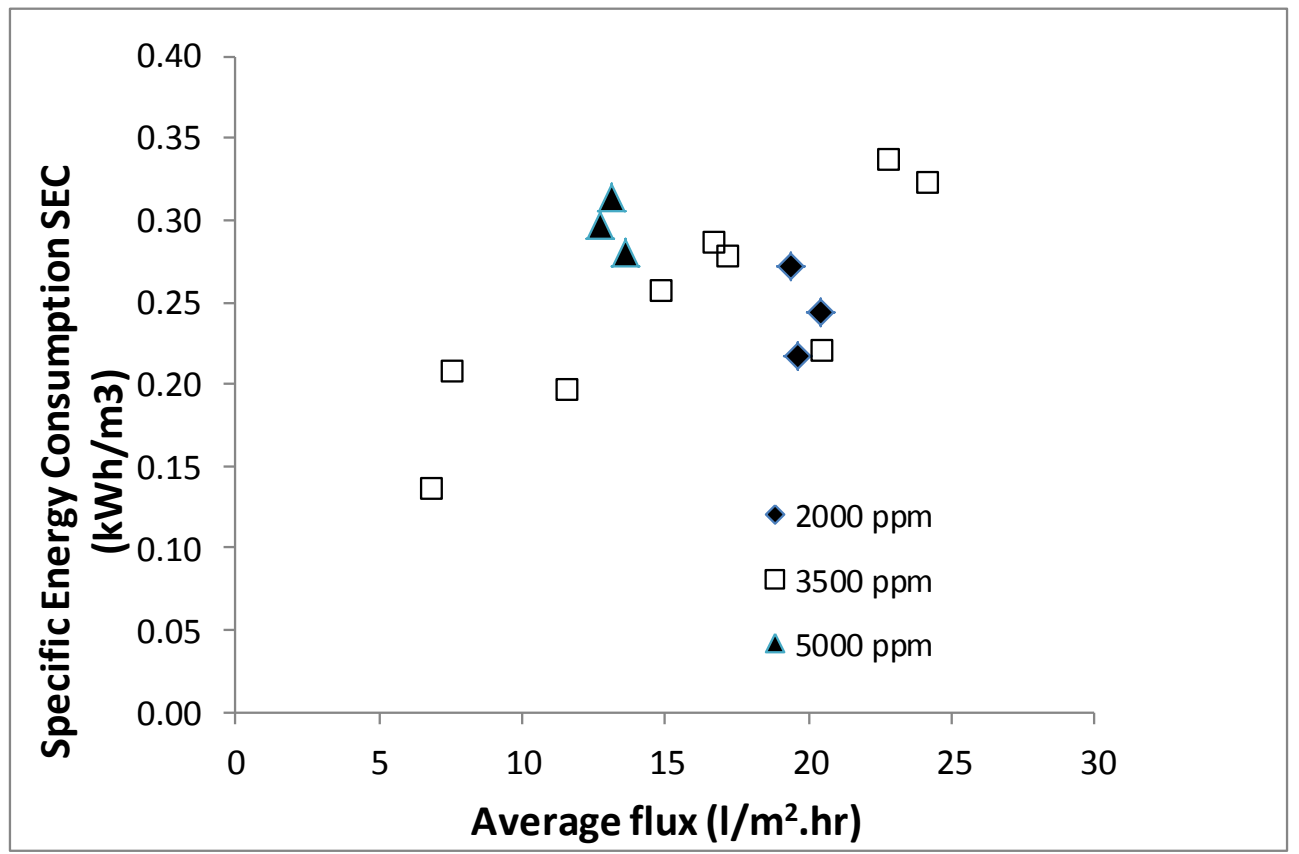

Figure 8: Summary of results of SEC at different salinities over a range of (a) different feed pressures (maximum occurring during pressurisation cycle) and (b) permeate flux (average over cycle). Decreasing the feed pressure decreases SEC, but at the expense of output flow rate. Note that each data point corresponds to one row of Table 1, and is obtained by integration under of a curve of the type shown in Fig.7. 
It is interesting to compare the SEC values obtained with the ideal minima of section 2 above. Thus the ECR values based on eq.[6] are plotted in Fig 9. This graph also shows the minimum ECR values ideally achievable by closed-loop desalination, or by single-stage continuous desalination with energy recovery device, according to eqs [12] and [13] respectively.

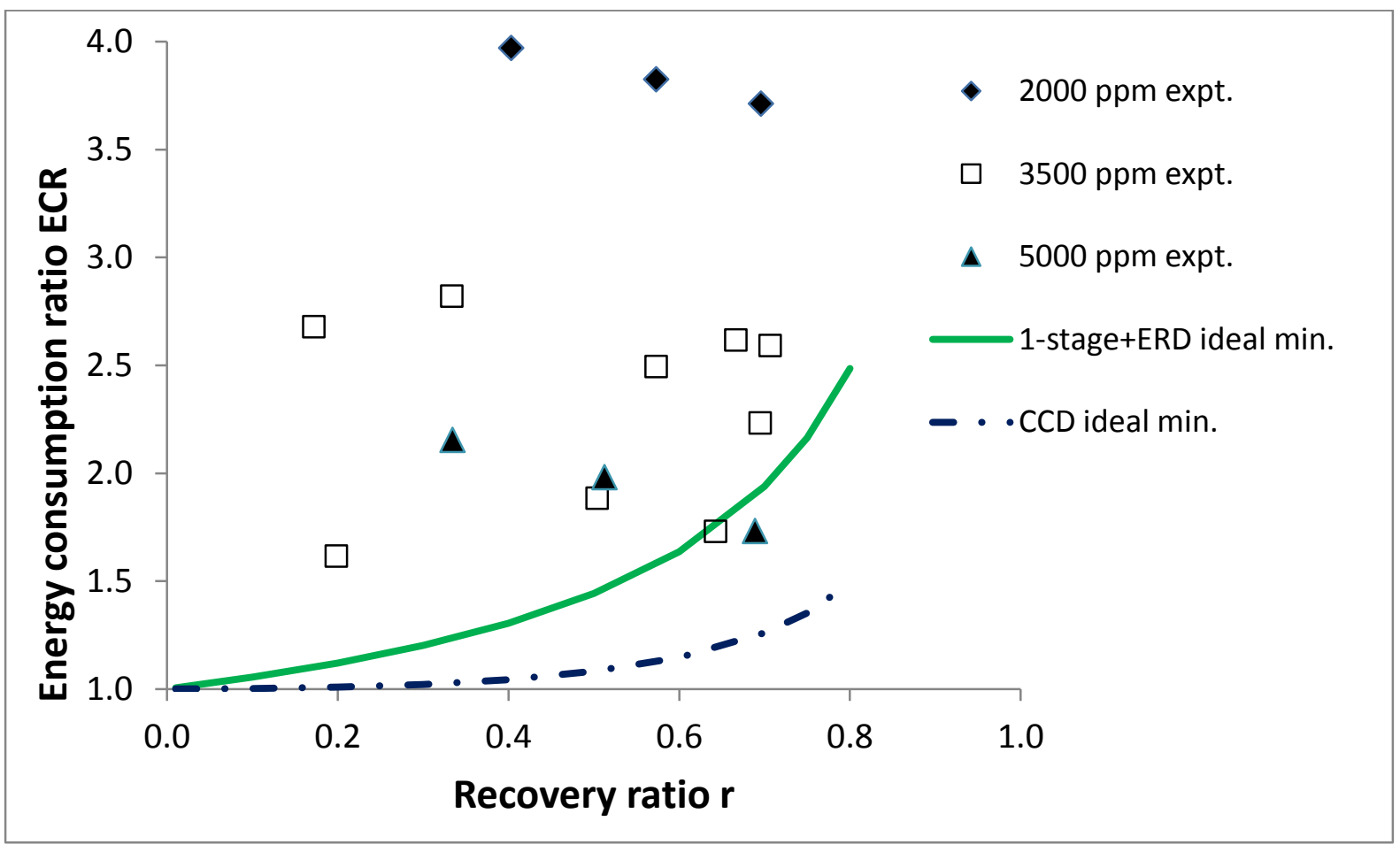

Figure 9: Energy consumption ratio vs. recovery ratio over the range of tests, compared to calculated ideal values for closed-circuit desalination (CCD) and for 1-stage continuous RO with energy recovery device (ERD).

It is interesting to note the ECR measured with the batch desalination system is in two cases better than that could ever be achieved with a single-stage continuous-flow with ERD. ECR values as low as 1.6 have been obtained in this work, meaning that the SEC only exceeds the theoretical minimum by $60 \%$, this being an unusually good result in the treatment of brackish water.

It was expected that lower recovery ratios would result in lower permeate salinities, due to the lower salt gradient across the membrane, but this was not observed in practice (Table 1). In a separate experiment, it was observed that permeate salinity tended to decrease sharply then increase gradually as the cycle progressed (Fig. 10). This is attributed to the dwelling of salt solution in the system between the fill and pressurisation phase, allowing salt to diffuse across the membrane before being flushed out at the start of pressurisation.

Complete raw data sets for the experiments are available on-line in reference 15. 


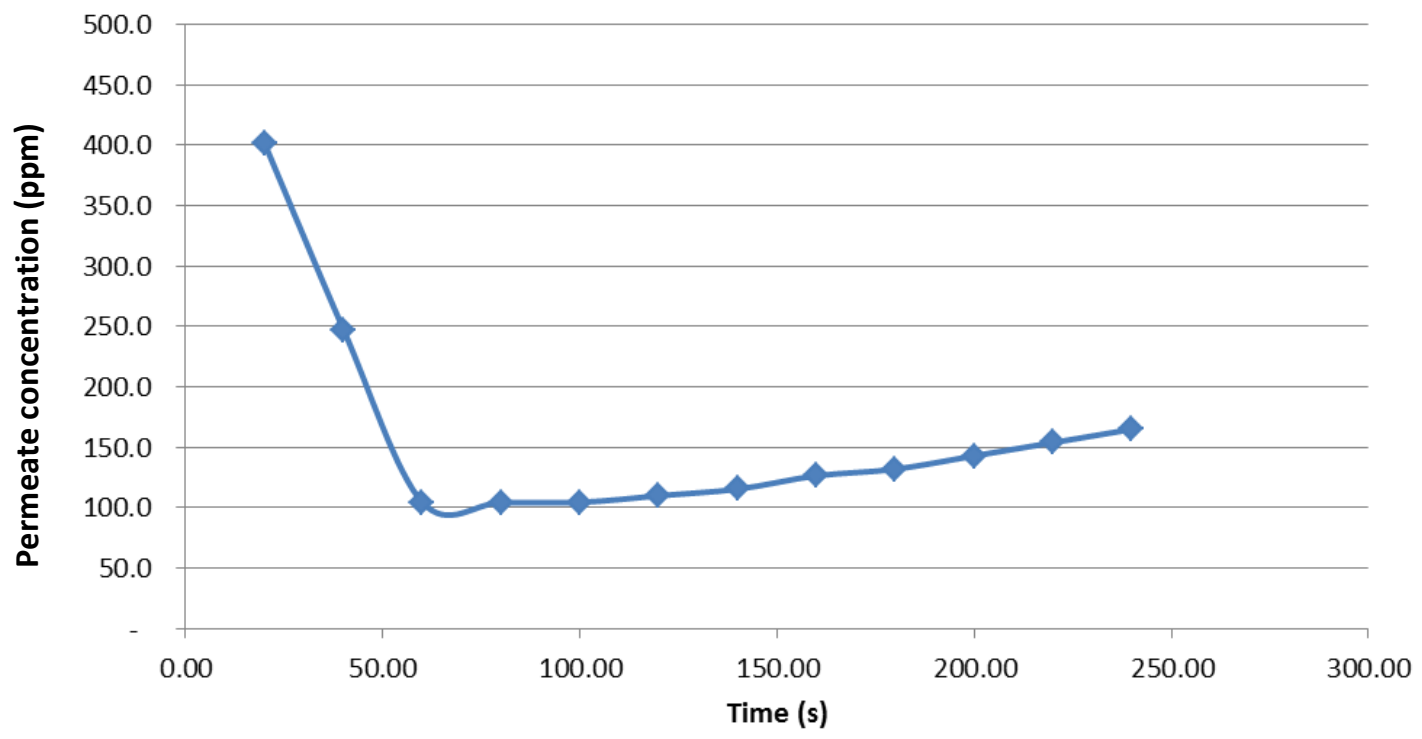

Figure 10: Permeate concentration over cycle duration (feedwater concentration 2000 ppm, nominal recovery ratio $70 \%)$

\section{Discussion}

Although this work has achieved its objective of demonstrating an efficient design of batch-RO system, supported by theoretical analysis and experimental evidence, several aspects need to be addressed to improve the characterisation and implementation of the design. For better characterisation, pumping energy losses need to be taken into account. For the specific high pressure pump borehole type pump used here, efficiency of around $30-43 \%$ has been measured in earlier experiments ${ }^{13}$. On the other hand, Efraty reported pump efficiency of $55 \%$ in a comparable CCD system for brackish water treatment ${ }^{10}$. It is thought that with careful selection of pump an efficiency of $50 \%$ should be routinely achievable. As regards the recirculation pump, Efraty reported $1.11 \mathrm{~kW}$ power consumption, which is $6.3 \%$ of the $17.59 \mathrm{~kW}$ he reported for the high pressure pump. Accordingly, the hydraulic SEC measured in this study of, for example, $0.286 \mathrm{kWh} / \mathrm{m}^{3}$ for 3500 ppm feed and $69.5 \%$ recovery (test 11 ), would increase to about $0.6 \mathrm{kWh} / \mathrm{m}^{3}$, which is still a very good result. In this test, the permeate was at 449 ppm concentration, thus within commonly accepted drinking water standards of 500 ppm.

For several of the tests, however, permeate concentration exceeded $500 \mathrm{ppm}$ and this would need to be lowered. This has been attributed partly to dwell time between phases of the cycle, an aspect to be improved through future automation of the system to allow rapid switching from one phase to the next. Low flux is another cause of high permeate salinity, leading to a trade-off between permeate quality and efficiency common to all RO systems. In the future, availability of low-pressure membranes or innovative materials such as zeolitic imidazolate frameworks ${ }^{14}$ could help to realise the potential for minimum SEC as shown in this work. Better control and reduction of the permeate salinity is also important for the characterisation of SEC and comparison to theoretical values, as 
high permeate salinity can reduce the transmembrane osmotic pressure and work input needed for separation.

\section{Conclusions and further work}

- We have described a new type of RO system for brackish water, which has been built from readily available components.

- It operates on a batch principle that is an improvement on closed-circuit desalination because it does not allow mixing of feed solution with the solution in the circuit. It is also an improvement on continuous-flow desalination.

- The system uses a positive displacement pump operated from a Solar Array Simulator to mimic photovoltaic modules.

- It has been tested to measure SEC over a range of feed salinities (2000 - 5000 ppm) and recovery ratios from $17 \%$ to $71 \%$. SEC was calculated based on hydraulic energy (and not on electrical energy supplied) giving values in the range 0.14 to $0.34 \mathrm{kWh} / \mathrm{m}^{3}$.

- The Energy Consumption Ratio, which compares SEC against ideal minimum, was in the range 1.6 to 4.0 . Some values at recovery ratios $>60 \%$ represent a decrease on the ideal minimum that could be achieved using a single-stage continuous system with energy recovery device; thus the performance of this type of standard system has been surpassed.

- Taking into account realistic pump losses, electrical SEC of about $0.6 \mathrm{kWh} / \mathrm{m}^{3}$ is achievable at $70 \%$ recovery.

- For better quality water output and better characterisation of SEC and ECR, it is desirable to reduce the salinity of the permeate in future studies.

- Highly permeable and selective membranes could in the future allow this system to approach the minimum SEC allowed by thermodynamic considerations, whereas conventional configurations cannot approach this minimum regardless of the type of membrane used.

Further work is needed to automate the rig which currently requires continuous supervision by 2 or 3 operators. We plan to deploy the system with a photovoltaic generator in places suffering from water and energy scarcity. It is expected that local artisans will carry out the construction to openaccess plans that have been published on-line ${ }^{15}$, using locally sourced materials where possible. Nonetheless, certain components like the RO membranes and borehole pumps will require specialised suppliers.

\section{Acknowledgements}

The authors acknowledge technical assistance from Mr. M. Turner and Mr. B. Curtis during construction of the prototype. 


\section{References}

${ }^{1}$ The Millennium Goals Report, UN, 2014.

${ }^{2}$ https://sustainabledevelopment.un.org [accessed $24^{\text {th }}$ February 2015].

${ }^{3}$ J. Sachs, The Age of Sustainable Development, Columbia University Press, 2015.

${ }^{4}$ M. Elimelech, W. A. Phillip, The future of seawater desalination: energy, technology and the environment, Science, 333 (2011), 712-717.

${ }^{5}$ E. Brian Smith, Basic Chemical Thermodynamics, $5^{\text {th }}$ Edt, Imperial College Press, 2004

${ }^{6}$ Salgado, B., J. M. Ortega, J. Blazheska, J. Sanz and V. García-Molina, High-permeability FILMTEC ${ }^{\text {TM }}$ and SEAMAXX ${ }^{\mathrm{TM}}$ Reverse Osmosis elements: a success story in the Canary Islands, Desalination and Water Treatment, 55 (2015), 3003-3011.

${ }^{7}$ M. Li, B. Noh, Validation of model-based optimisation of brackish water reverse osmosis (BWRO) desalination, Desalination, 304 (2012), 20-24.

${ }^{8}$ P. A. Davies, J. Orfi, Self-powered desalination of geothermal saline groundwater: technical feasibility, Water, 6 (2014), 3409-3432.

${ }^{9}$ L. Szücz, A. Szücs, US Patent 4983301, 1991.

${ }^{10}$ A. Efraty, Closed circuit desalination series no-4: high recovery low energy desalination of brackish water by a new single stage method without any loss of brine energy, Desalination and Water Treatment, 42 (2012) 262-268.

${ }^{11}$ T. Y. Qiu, P. A. Davies, Comparison of configurations for high-recovery inland desalination systems, Water, 4 (2012), 690-706.

12 M. Li, Reducing specific energy consumption in Reverse Osmosis (RO) water desalination: an analysis from first principles, Desalination 276 (2011), 128-135.

${ }^{13}$ P. A. Davies and A. K. Hossain, Development of an integrated reverse osmosis-greenhouse system driven by solar photovoltaic generators, Desalination and Water Treatment, 22 (2010) 1-13.

${ }^{14}$ K. M. Gupta, K. Zhang, and J. Jiang., Water Desalination through Zeolitic Imidazolate Framework Membranes: Significant Role of Functional Groups, Langmuir, 31 (2015) 13230.

15 J. Wayman, Brackish Ground Water Desalination using Solar Reverse Osmosis, MEng Dissertation, Aston University, 2015, available at: http://dx.doi.org/10.13140/RG.2.1.1256.6881 